\title{
Risk behaviour among Aboriginal and Torres Strait Islander gay men: comparisons with other gay men in Australia
}

\author{
Chris G. Lawrence ${ }^{\mathrm{A}, \mathrm{C}}$, Patrick Rawstorne ${ }^{\mathrm{B}}$, Peter Hull ${ }^{\mathrm{B}}$, Andrew E. Grulich ${ }^{\mathrm{A}}$, \\ Scott Cameron ${ }^{\mathrm{C}}$ and Garrett P. Prestage A,D $^{\mathrm{D}}$

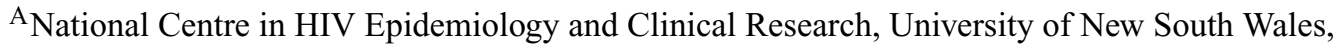 \\ Sydney, NSW 2000, Australia. \\ ${ }^{B}$ National Centre in HIV Social Research, University of New South Wales, Sydney, NSW 2000, Australia. \\ ${ }^{\mathrm{C}}$ National Centre in Epidemiology and Population Health, Australian National University, Canberra, ACT 2601, Australia. \\ ${ }^{D}$ Corresponding author. Email: gprestage@nchecr.unsw.edu.au
}

\begin{abstract}
Objectives: To determine any differences in HIV-risk and drug-use behaviour among Aboriginal and Torres Strait Islander gay men and other gay men in Australia. Methods: The Gay Community Periodic Survey is a repeated cross-sectional prevalence study of the sexual and drug use behaviours of Australian gay men conducted since 1996. Responses from Aboriginal and Torres Strait Islander (ATSI) gay men were compared with those from non-ATSI gay men for the years 2000-2004. Results: Of 34708 responses collected in major Australian cities over a 6-year period, 1208 identified as Aboriginal or Torres Strait Islander. There was little difference between ATSI and non-ATSI men in the reported prevalence of HIV, though ATSI gay men were more likely than non-ATSI gay men to engage in unprotected anal intercourse with casual partners and to inject illicit drugs but were more likely to have been recently tested for HIV. Conclusions: These ATSI gay men were at increased risk of HIV and other blood-borne viruses, though this may be due to differences in socio-economic status as much as cultural background. These findings indicate the continued need for targeted sexual and injecting-drug-use health interventions among this population.
\end{abstract}

Additional keywords: injecting drug use, sexual behaviour, unprotected anal intercourse.

\section{Introduction}

The National Indigenous Australians Sexual Health Strategy (NIASHS) ${ }^{1}$ suggests that within many Aboriginal and Torres Strait Islander (ATSI) communities, HIV has been thought of as affecting white gay men only, and argues that ATSI men who have sex with men (MSM) face discrimination due to both their aboriginality and their sexuality. Yet little research to determine who among this population is at greatest risk has yet been undertaken.

Although the transmission of HIV among homosexuallyactive Australian men has been relatively well researched, ${ }^{2}$ less is known about HIV transmission among homosexuallyactive ATSI men. Even less is known about how cultural factors specific to the ATSI population may influence the sexual behaviours of this group.

Existing public-health strategies in Australia have, over many years, been relatively successful in slowing the spread of HIV among homosexually-active men. ${ }^{2}$ These strategies have predominantly addressed either the general population, especially in the early phases of the epidemic, or gay men of Anglo Saxon background and gay communities in inner urban areas of the major cities.

Homosexually-active ATSI men are harder to contact than non-ATSI men, given that they are less concentrated in urban populations, less likely to identify as gay due to cultural taboos and attachment to traditional communities, less likely to be literate and less likely to have confidence in health institutions that they consider do not display sensitivity to their needs. ${ }^{3}$

Given the problem of reaching this group, governmentfunded organisations have developed campaigns and resources that specifically address sexual-health issues in the ATSI population. However, the efficacy of such campaigns has largely been evaluated on an anecdotal level. ${ }^{4,5}$

Moreover, the limited research that has been undertaken in relation to HIV in indigenous communities often relates not to Australia's ATSI population but, rather, to Canadian Aboriginals, American Indians and Alaskan Natives. ${ }^{6,7}$ These studies have shown that HIV, sexually transmissible infections (STIs) and other blood-borne viruses (BBVs) are 
significant causes of morbidity in indigenous people. In Australia, among indigenous male populations, poor sexualand reproductive-health issues have been attributed to poor education, low socio-economic living standards and highunemployment rates. ${ }^{8}$

In the present study, we compare, for the first time, Gay Community Periodic Surveys (GCPS) data about HIVrisk and drug-use behaviours among ATSI and non-ATSI gay men.

\section{Methods}

The GCPS, which was originally conducted in Sydney in 1996, has since been repeated at regular intervals in major Australian cities and the methods have been previously described. ${ }^{9-15}$ In 1998, respondents were first asked specifically: 'Are you of Aboriginal or Torres Strait Islander origin?' Data included here are for the period from 2000 to 2004 .

\section{Questionnaire}

A self-administered questionnaire was used and included questions on sexual behaviours, condom use and relationship status, HIV testing practice and HIV serostatus, antiretroviral treatment (ART), recreational drug use including injecting drug use (IDU), sexual identity and measures of gay community attachment. Complete wording of the questions used has been previously reported..$^{9-15}$ On average, men usually completed the questionnaire in about $10 \mathrm{~min}$. No assistance was provided for completion of the questionnaire.

\section{Participants}

Participants were recruited from a range of gay community venues, clinics and events at each location. ${ }^{11}$ Men were eligible to participate if they had had sex with another man within the previous 5 years. We have included all men who completed a questionnaire for the survey between 2000 and 2004.

\section{Data analysis}

Univariate analysis was undertaken using SPSS (SPSS Inc., Chicago, IL), calculating $P$-values using the $\chi^{2}$-test or Fisher's exact test. Descriptive analysis compared ATSI and non-ATSI respondents with respect to demographic variables, sexual identity and gay community attachment, sexual and injecting-drug-use behaviours, HIV serostatus and HIV testing behaviours. Trend data were analysed separately for ATSI and non-ATSI men and it was determined that trends over time applied equally to both groups. Results should be interpreted with caution because some respondents may have completed the survey on more than one occasion: in February 1997, 26.2\% of Sydney respondents indicated they had completed the survey in 1996.

A multivariate logistic regression was undertaken to determine independent associations with sexual-risk behaviour, in this case unprotected anal intercourse with casual partners (UAIC), to determine if ATSI status was an independent risk factor.

\section{Results}

The proportion of ATSI respondents was lowest in Canberra and highest in Brisbane. These proportions are consistent with Australian Bureau of Statistics data, which show that the total population in Queensland, during the December 2004 quarter, was 3919500 persons. Of this total, 3.2\% identified as ATSI. In the same period in the Australian
Capital Territory, the total population was 324 300, with $1.2 \%$ identifying as ATSI. ${ }^{16}$ Overall, in the current study, between 2000 and 2004, there were 1208 ATSI respondents and 33497 non-ATSI respondents (Table 1). Although numbers did not permit detailed analysis by city, the findings presented here were generally true regardless of from which city the men were recruited.

The study found that ATSI gay men included in the survey had a mean age of 33 years, whereas non-ATSI men were slightly older, with a mean age of 35 years $(P=0.001)$. One-quarter $(27.1 \%)$ of ATSI men and $20.8 \%$ of non-ATSI men were not in employment $(P<0.001)$. When employed, ATSI men were less likely than non-ATSI men to be in managerial or professional positions (28.7 and 39.3\% respectively: $P<0.001)$. One-third (33.9\%) of ATSI men had received university education, compared with $46.6 \%$ of nonATSI men $(P<0.001)$.

It was found that ATSI men were less likely to identify as homosexual: $85.2 \%$ of ATSI men and $90.4 \%$ of non-ATSI men identified as gay $(P<0.001)$. They were also less likely to indicate having 'mainly' gay friends $(P=0.006)$.

There was no difference between ATSI and non-ATSI respondents in reported HIV prevalence: $11.3 \%$ of ATSI men and $10.6 \%$ of non-ATSI men reported being HIV-positive. Though not a large difference proportionally, ATSI men were more likely to have been recently tested for HIV; among those men who were not HIV positive, $64.6 \%$ of ATSI men and $59.2 \%$ of non-ATSI men had been tested for HIV in the 12 months prior to completing the survey $(P<0.001)$. Men who reported being HIV-positive were asked if they were currently on antiretroviral treatments (ART). Two-thirds (66.2\%) of HIV-positive non-ATSI men and three-quarters $(77.5 \%)$ of HIV-positive ATSI men were on ART $(P=0.005)$.

During 2000 and 2001, men in Sydney, Melbourne, Perth and Canberra were asked if they had been diagnosed with specific sexually transmissible infections (STIs) in the 12 months prior to the survey. The number of ATSI respondents was small and so these data should be interpreted with caution (ATSI $=208$, non-ATSI $=9941$ ). We found that ATSI men were more likely than non-ATSI men to report episodes of gonorrhoea (9.6 and $6.2 \%$ respectively: $P=0.035)$ and syphilis (5.3 and 2.0\%: $P=0.004)$. Though not statistically significant, this tended also to be the case for chlamydia (7.7 and 5.1\%: $P=0.068$ ).

Respondents were asked about sexual and drug-using behaviours, which showed that ATSI men were more likely to use most types of illicit drugs than non-ATSI men, including marijuana (51.4 and $43.6 \%$ respectively; $P<0.001$ ), heroin (5.5 and 1.4\% respectively; $P<0.001)$ and speed (34.8 and $28.0 \%$ respectively; $P<0.001$ ). They were also more likely to have injected illicit drugs: $10.8 \%$ of ATSI men and $5.9 \%$ of non-ATSI men had injected drugs in the 6 months prior to being surveyed $(P<0.001)$. 


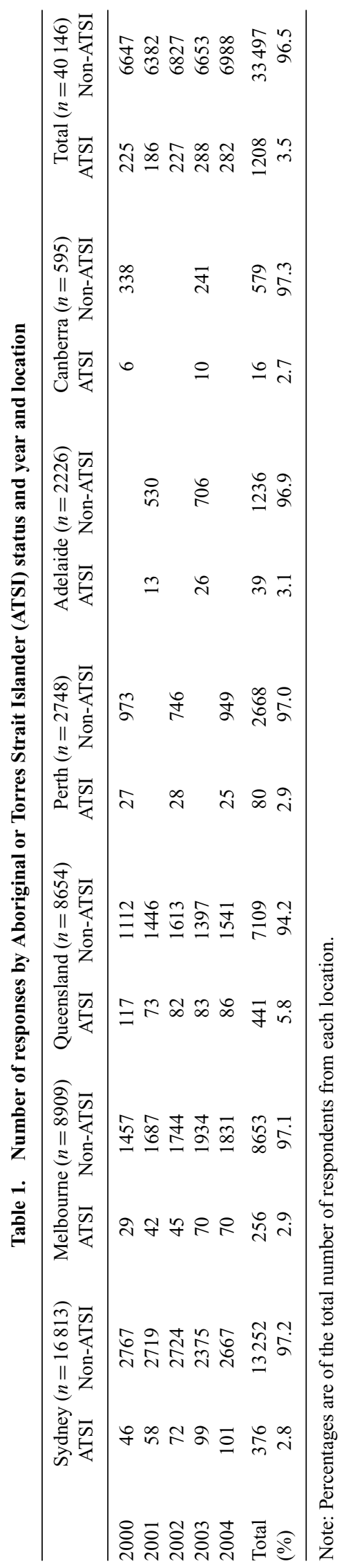


Both ATSI and non-ATSI men were equally likely to have had sex with casual partners in the preceding 6 months. They were also equally likely to have had sex with regular partners. However, ATSI men were more likely than non-ATSI men to engage in UAIC: $23.5 \%$ of ATSI men and $20.7 \%$ of nonATSI men had engaged in UAIC in the preceding 6 months $(P=0.010)$. They were, however, no more likely to engage in UAI with their regular partners.

In the multivariate analysis of factors associated with sexual-risk behaviour, engaging in UAIC was not associated with being of Aboriginal or Torres Strait Islander background (Table 2). Factors that were associated with UAIC were being HIV-positive, having more sex partners in the previous 6 months, being surveyed in cities other than Melbourne, any use of illicit drugs and not being employed as a manager or professional. Only the latter two of these items were associated with being of ATSI background in the univariate analysis. Other items that were tested in the analysis were: age, sexual identity and number of gay friends.

\section{Discussion}

There was no difference in the reported rate of HIV infection between these ATSI and non-ATSI men, even though the ATSI men were somewhat more likely to engage in behaviours associated with the transmission of HIV. This difference in risk behaviour, although significant at a univariate level, was only a small difference in absolute terms and being of ATSI background was not independently associated with UAIC in the multivariate analysis.

Table 2. Factors associated with engaging in UAIC (multivariate logistic regression analysis)

\begin{tabular}{|c|c|c|c|}
\hline Variable & $\begin{array}{l}\text { Adjusted } \\
\text { odds ratio }\end{array}$ & $95 \% \mathrm{CI}$ & $P$ value \\
\hline Location of recruitment & & & $<0.001$ \\
\hline Sydney & 1.00 & & \\
\hline Melbourne & 0.764 & $0.710-0.822$ & \\
\hline Queensland & 1.058 & $0.980-1.142$ & \\
\hline Adelaide & 1.001 & $0.891-1.125$ & \\
\hline Perth & 0.926 & $0.789-1.085$ & \\
\hline Canberra & 0.851 & $0.590-1.227$ & \\
\hline Employment & & & $<0.001$ \\
\hline Managerial/professional & 1.00 & & \\
\hline Para-professional & 1.126 & $1.012-1.252$ & \\
\hline Trade & 1.194 & $1.030-1.384$ & \\
\hline Clerical and sales & 1.202 & $1.116-1.295$ & \\
\hline Plant operator/Labourer & 1.458 & $1.258-1.691$ & \\
\hline Not employed & 1.237 & $1.143-1.340$ & \\
\hline HIV status & & & $<0.001$ \\
\hline HIV-positive & 1.00 & & \\
\hline HIV-negative & 0.379 & $0.349-0.411$ & \\
\hline Untested/Results unknown & 0.445 & $0.396-0.499$ & \\
\hline Any illicit drug use & 1.502 & $1.407-1.604$ & $<0.001$ \\
\hline Number of male sex partners & 2.575 & $2.492-2.660$ & $<0.001$ \\
\hline
\end{tabular}

It has been reported that, in some rural Aboriginal communities, men who engage in risky sexual behaviours are more likely to seek tests for the presence of HIV. ${ }^{16}$ Given that ATSI gay men were slightly more likely to engage in UAIC - a behaviour well understood to be associated with HIV transmission ${ }^{17}$ - it is not surprising that they were more likely to have been recently tested for HIV and that they were more likely to also report recent infection with other STIs. Nonetheless, indigeneity was not independently associated with UAIC. Factors associated with UAIC included other indicators of risk behaviour, such as illicit drug use or having multiple sex partners, as well as occupational and employment status. Socio-economic status may be of greater consequence than cultural background in accounting for sexual-risk behaviour in this population.

To date, there has been relatively little research into injecting drug users of ATSI background. ${ }^{1}$ National monitoring of needle and syringe programs has reported a low prevalence of HIV infection resulting from IDU for both ATSI and non-ATSI populations. ${ }^{18}$ It is, however, difficult to determine the level of hepatitis $\mathrm{C}(\mathrm{HCV})$ infection among indigenous Australians, because indigenous status is not recorded in the notifiable disease statistics of several states and territories. ${ }^{19}$ Nonetheless, the Australian hepatitis C Surveillance Strategy ${ }^{20}$ identified indigenous Australians as being at increased risk, compared with the general population, of $\mathrm{HCV}$ transmission. In our univariate analysis, injecting drug use was higher among indigenous than nonindigenous gay men, suggesting that $\mathrm{HCV}$ infection is a potential issue in this population. ${ }^{21,22}$

According to these findings, ATSI gay men represent at least as important a target group for public-health intervention as do other gay men. The national HIV/AIDS and BBV strategies suggest that gay men, people who inject drugs and ATSI populations are at increased risk of infection. The ATSI gay men in this study are at increased risk, though this may be a function of their socio-economic status and marginalisation rather than their indigeneity and they also represent several of the identified priority areas so they, therefore, require a targeted response.

These samples, recruited through gay community sites, are not representative of all men who have sex with men (MSM). In particular, men who have little or no contact with organised gay communities are unlikely to be represented in the surveys. With respect to ATSI MSM in particular, we cannot know what proportion participates in local gay communities. It may be that the ATSI men in this sample, due to their close connections with gay community, are more informed about practices that are at risk of HIV and STI transmission than MSM who are not so connected, or, equally, that MSM who do not participate in gay community may be more cautious about the risk of HIV and STI infection and so are less likely to engage in risk behaviour. Whichever is the case, there is a clear need for further research that 
targets ATSI MSM who do not participate in local gay community activities.

Nonetheless, these surveys have recruited many homosexually-active men who identified both as gay and as ATSI. These data provide, for the first time, some insights into the risk behaviour of this group of men. Overall, the ATSI and non-ATSI men in this survey are more alike than different. Where differences do emerge, they indicate that ATSI men are at increased risk of infection by HIV and other blood-borne viruses, but are also, like their heterosexual counterparts, more disadvantaged on several socio-economic indicators and it may be that this relative disadvantage underlies their greater risk of infection.

\section{Conflicts of interest}

None exist.

\section{Acknowledgements}

The authors thank the respective state AIDS Councils and PLWHA organisations for collaboration with the project, and the men who have participated in the Periodic Surveys in each state. The National Centre in HIV Epidemiology and Clinical Research, and the National Centre in HIV Social Research, are funded by the Commonwealth Department of Health and Ageing.

Sponsorship: this study was supported by the Health Departments in the states of New South Wales, Victoria, Queensland, South Australia, Western Australia, and the Australian Capital Territory.

\section{References}

1 Commonwealth Department of Health and Family Services. The national indigenous Australians sexual health strategy 1996-97 to 1998-99. A report of the ANCARD working party on indigenous Australians sexual health. Canberra; Australian Government Publishing Service; 1997.

2 Commonwealth Department of Health and Aged Care. National HIV/AIDS Strategy 1999-2000 to 2003-2004. Canberra: Changes and Challenges, Commonwealth of Australia; 2002.

3 Australian Federation of AIDS Organisations (AFAO). The National Indigenous Gay and Transgender Project: consultation report and sexual health strategy. Sydney: Australian Federation of AIDS Organisations; 1998.

4 Plummer D, Forrest B. Factors affecting Indigenous Australians access to sexual health clinical service. Venereology 1999; 12(2): $47-51$.

5 Van der Sterren A, Anderson I. Building responses to blood-borne virus infection among Kooris using injecting drugs - improving the link between policy and service delivery. Discussion Paper No. 7. Melbourne: VicHealth Koori Health Research and Community Development Unit; 2002.

6 Craib K, Spittal P, Wood E, Laliberte N, Hogg R, Li K et al. Risk factors for elevated HIV inicidence among Aboriginal injection drug users in Vancouver. Can Med Assoc J 2003; 168(1): $19-24$.
7 Bertolli J, McNaghten A, Campsmith M, Lee L, Leman R, Bryan R et al. Surveillance systems monitoring HIV/AIDS and HIV risk behaviours among American Indians and Alaska Natives. [The Guilford Press] AIDS Educ Prev 2004; 16(3): 218-37. doi: 10.1521/aeap.16.3.218.35442

8 Adams M, de Kretser D, Holden C. Male sexual and reproductive health among the Aboriginal and Torres Strait Islander population. Rural and Remote Health 2003; 3. Available online at: http://rrh.deakin.edu.au [verified July 2006].

9 Van de Ven P, Kippax S, Crawford J, French J, Prestage G, Grulich A et al. Sexual practices in a broad cross-sectional sample of Sydney gay men. Aust N ZJ Public Health 1997; 21(7): 762-6.

10 Hull P, Van de Ven P, Prestage G, Kippax S, Ngo P, WentzlaffEggebert M et al. Gay Community Periodic Survey: Adelaide 2003. Sydney: National Centre in HIV Social Research, The University of New South Wales; 2003.

11 Hull P, Van de Ven P, Rawstorne P, Prestage G, Kippax S, Brown $\mathrm{S}$ et al. Queensland Gay Community Periodic Survey: 2004. Sydney: National Centre in HIV Social Research, The University of New South Wales; 2004.

12 Hull P, Van de Ven P, Prestage G, Rawstorne P, Grulich A, Crawford J et al. 2002. Gay Community Periodic Survey: 19962002. Sydney: National Centre in HIV Social Research, The University of New South Wales; 2003.

13 Hull P, Van de Ven P, Prestage G, Rawstorne P, Kippax S, Horn G et al. Melbourne Gay Community Periodic Survey: 2003. Sydney. National Centre in HIV Social Research, The University of New South Wales; 2003.

14 Hull P, Van de Ven P, Prestage G, Kippax S, Schamburg K, Coase D. Gay Community Periodic Survey: Canberra, 2003. Sydney: National Centre in HIV Social Research, The University of New South Wales; 2003.

15 Hull P, Brown G, Van de Ven P, Prestage G, Rawstorne P, Kippax S et al. Gay Community Periodic Survey: Perth 2002. Sydney: National Centre in HIV Social Research, The University of New South Wales; 2002.

16 Australian Bureau of Statistics. Australian demographic statistics, December quarter 2004, catalogue 3101.0. Canberra: Australian Bureau of Statistics; 2004.

17 Miller PJ, Torzillo PJ. Private business: the uptake of confidential HIV testing in remote Aboriginal communities on the Anangu Pitjantjara Lands. Aust NZ J Public Health 1998; 22(6): 700-3.

18 Commonwealth Department of Health and Aged Care, National Hepatitis C Strategy 1999-2000 to 2003-2004. Canberra; Commonwealth of Australia; 2000.

19 Van De Ven P, Rawstorne P, Treloar C, Richter J. HIV/AIDS, hepatitis and sexually transmissible infections (STIs) in Australia, annual report of behaviour, 2004. Sydney: National Centre in HIV Social Research in collaboration with Australian Research Centre in Sex, Health and Society, and National Centre in HIV Epidemiology and Clinical Research; 2004.

20 Correll P, MacDonald M, Dore G. Hepatitis C infection in indigenous communities in Australia. Canberra: Commonwealth Department of Health and Aged Care; 2000.

21 National Centre in HIV Epidemiology and Clinical Research. HIV/AIDS, viral hepatitis and sexually transmissable infections in Australia: annual surveillance report 2003. Sydney: National Centre in HIV Epidemiology and Clinical Research; 2003.

22 Australian Institute of Health and Welfare. Statistics on drug use in Australia 2002 (Cat. No. PHE 43 (Drug Statistics Series no. 12). Canberra: Australian Institute of Health and Welfare; 2003.

Received 11 October 2005, accepted 16 June 2006 